\title{
Kommission Hüftsonografie nach Graf
}

Sehr zu reden gaben die teils horrenden (über 100000 sFr.) Rückforderungen der Krankenkassenorgane wegen angeblich oder tatsächlich nicht erfolgter Rezertifizierung von Fähigkeitsausweis-Inhabern. Glücklicherweise handelte es sich meistens nur um administrative Versäumnisse. Dennoch sei darauf hingewiesen, dass die Rezertifizierungspflicht ernst genom- men werden muss. Die Kommission verschickt denn auch immer rechtzeitig entsprechende Erinnerungsbriefe.

Im Jahr 2017 müssen über 150 Inhaber rezertifizieren, was einen erheblichen Kursaufwand bedeutet.

\section{Beat Dubs}

Präsident Kommission Hüftsonografie 